\title{
Effect of Dimethoate Residues on Soil Micro-arthropods Population in the Valley of Zendan,Yemen
}

\section{${ }^{1}$ MOHAMMED AHSSAN AL-HAIFI; ${ }^{2}$ KHAN, M Z; ${ }^{3}$ ABDULLAH MURSHED, V; ${ }^{*}$ GHOLE, $\mathrm{S}$}

\author{
${ }^{1 *}$ Department of Environmental Sciences, University of Pune, Pune - 411007, India. \\ Tel. +91-20-25691195, Fax +91-20-25691728. \\ ${ }^{2}$ Department of Zoology, University of Pune, India. \\ ${ }^{3}$ Department of Entomology, Agriculture Collage, University of Sana, a, Yemen.
}

\begin{abstract}
The present study aimed to screen the effect of overuse of the insecticide Dimethoate and its residues within $0-15 \mathrm{~cm}$ soil layer on the soil micro-arthropods population, which play a very important role in maintenance of the fertility of the soil. The valley of Zendan is located in Arhab Destrict, Sana'a Governorate, Yemen. The valley is about $50 \mathrm{~km}$ north-east of Sana'a city and this geographical area is a large producer of Qat (Catha edulis Forsk); the plant which most of the people in the country chew. In this study the valley divided into three stations, each station contained three treated substations and three control substations. The control substations selected from the farms, which are historically free from pesticides. Due care has been taken to insure that the treated sub-stations were from the closest area to the control substations. The average use of Dimethoate $40 \%$ E.C is $1-2$ $\mathrm{ml} / \mathrm{L}$ water. The treatment replication was 1-3 times within the period of 2-3 weeks. In this study also, we analyzed the total concentration of Dimethoate, and its metabolite; Omethoate in the soil layer of $0-15 \mathrm{~cm}$. The analysis of Dimethoate and Omethoate residues from representative soil samples covered the major part of the Zendan valley was done by the technique of LC-MS, and the results revealed that the detected levels ranged from 0.914 to 5.180 $\mathrm{mg} / \mathrm{kg}$ air-dried soil for Dimethoate residues and 0.001 to $0.067 \mathrm{mg} / \mathrm{kg}$ air-dried soil for Omethoate residues. For studying the effect of Dimethoate residues on the soil micro-arthropods population, soil samples from each substation were collected with core sampler. The soil micro-arthropods were extracted for 48 hours and collected in vials containing $70 \%$ alcohol by using the extraction funnels technique. The number and type of soil microarthropods extracted from each substation were separated and recorded and the data obtained was analyzed. The outcomes of the study revealed that Dimethoate and Omethoate residues are beyond the Total Threshold Limit Concentration (TTLC) and significantly reduced the population of the non-target soil micro-arthropods that included mainly mites, collembolans, beetle larvae, trips, cutworms, symphyla and seed corn maggot. Mites and collembolans were the most affected micro-arthropods by Dimethoate and Omethoate residues. The reduction in the soil microarthropods population varied from $59 \%$ to $69 \%$ as compared to its population in control substations. The maximum decline of soil microarthropods was found to be in substations where the highest residues of Dimethoate and Omethoate were recorded. Thus indiscriminate use of pesticides such as Dimethoate will definitely affect the soil fertility in the area and that will reduce the crop yield in future. @JASEM
\end{abstract}

Dimethoate (Perfekthion) is a widely used insecticide in Yemen for controlling of pests during the cultivation of Qat (Catha edulis Forsk). Arthropods constitute well over one-half of the species of higher life on the planet and are the dominant terrestrial life form on the planet (Redak, 2000). Apart from soil microorganisms, soil is known to contain many other soil fauna such as mites, collembolans, proturans, diplurans, centipedes, symphylans, pseudo-scorpions, fly larvae, beetle grubs etc. Soil fauna play an important role in soil fertility and humification, in addition to their role in many food chains and biochemical processes of decomposition. It is likely that insecticides applied to the fields for pests control contaminate the soil, and may harm several nontarget soil fauna. Rajagopal et al. (1990) reported that soil fauna that included mainly mites and collembolans were affected by insecticide application in the field. The effect of pesticides on the soil mesofauna is complex because of their action on both predacious and non-predacious groups. Therefore, several workers have reported increased population of collembolan and mites after the use of pesticides, mainly because of mortality of predacious mites, which exercise a great check on other mites and collembolan, (Veeresh and Rajagopal, 1989). Epstein et al. (2000) reported the effect of broad-spectrum insecticides on Epigeal Arthropod biodiversity in Pacific Northwest apple orchards. They reported that the highly mobile invertebrates were strongly susceptible to application of broad spectrum neural active insecticides. Pesticides input in Yemen is increasing year by year. The input increased from 730 tones in 1994 to 1866 tones in 1996. These figures do not include the pesticides brought into the country from illegal channels (Al-Munibari, 2002). According to FAO, in Africa and the Near East, 1,511 tons of obsolete pesticides have been disposed 
in 10 countries; Yemen is one of them. This tremendous input of pesticides to the ecosystem ultimately will affect the soil fauna. In the present study, we have focused on the analysis of soil contamination with Dimethoate in Zendan Valley and its ecotoxicological effects on the soil microarthropods population. There are no baseline data available about the soil contamination with pesticides and the soil fauna of the study area

\section{MATERIALS AND METHODS}

The study area: The valley of Zendan is located in Arhab Destrict, Sana'a Governorate. This valley is about $50 \mathrm{~km}$ northeast of Sana'a and this geographical area is a large producer of Qat; the plant which most of the people in the country chew. In the present study the valley was divided into three stations, the first station was the upper valley (S1), second station was the mid-valley (S2) and the third station was the lower valley (S3). In each station, three substations selected for control and three substations were selected for treatment. The control substations selected from the farms, which are historically free from pesticides. Due care has been taken to insure that the treated sub-stations were from the closest area to the control substations. The average use of Dimethoate $40 \%$ E.C was $1-2 \mathrm{ml} / \mathrm{L}$ water. The treatment replication was 1-3 times within a period of 2-3 weeks, (Guide of Pesticide Use in the Republic of Yemen, Agriculture and Water resources Ministry, 1990). The geographical coordinate is 1500 N, 4800 E.

Treatment and sample collection: Soil samples from each substation were collected on the day $5^{\text {th }}$ after spraying of Dimethoate. The samples were drawn with core sampler (the diameter of the sampler was $10 \mathrm{~cm}$ and its depth was $15 \mathrm{~cm}$ ) and the soil samples were collected in aluminum cans (D. Rajagopal et al, 1990). The soil samples were then emptied into the extracting funnels. The soil micro-arthropods were extracted for 48 hours and collected in vials containing $70 \%$ alcohol. Then identified under stereo binocular microscope, the number and type of soil micro arthropods extracted from each of the treatments were separated and recorded and the data obtained was analyzed. All experiments were replicated with three independent sets. The physicochemical properties of representative soil samples were studied according to Gupta (2000), in which ferrous, zinc, manganeous, electric conductivity (EC), $\mathrm{pH}$, and texture class of the soil were determined.

Extraction of Dimethoate and Omethoate from Soil Samples: (TNO Laboratories, Netherland)

Dimethoate and Omethoate (its metabolite in soil) residues were extracted from the soil samples by adding $0.5 \mathrm{gm}$ activated florisil (activated at $110^{\circ} \mathrm{C}$ for $1 \mathrm{hr}$ ), $0.5 \mathrm{gm}$ activated charcoal and $10 \mathrm{gm}$ anhydrous $\mathrm{Na}_{2} \mathrm{SO}_{4}$ to 100 gm air-dried soil samples in a soxhalet extractor. The extraction has been done by hexane : aceton $(90: 10)$ for 6 hours. The extract concentrated in Rotatory Vacuum Evaporator (R.V.E) until dryness and reconstituted with $5 \mathrm{ml}$ methanol. The concentration of Dimethoate and Omethoate were calculated by using the following formula (TNO Laboratories, Netherland):

$\frac{A_{s}}{A_{s d}} \times \frac{C_{s d}}{W_{s}} \times D F$

where As = area of sample, $A_{s d}=$ area of standard, $\mathrm{C}_{\mathrm{sd}}=$ concentration of standard, $\mathrm{W}_{\mathrm{s}}=$ weight of sample and DF = dilution factor

Liquid Chromatography Mass Spectrophotometry: LCMS analysis was carried out using an APE2000 Liquid Chromatograph Mass Spectrophotometer (Applied Biosystem Co., Holland) equipped with C18 column, $15 \mathrm{~cm} \mathrm{X} 4.6 \mathrm{~mm}$ and MS detector. The temperature was $450^{\circ} \mathrm{C}$, retention time was 3.64 minutes for Dimethoate and 1.90 minute for Omethoate, (the reference of the standard was obtained from TNO Laboratories, Netherland).

\section{RESULTS AND DISCUSSION}

The basic physicochemical properties of the soil samples were presented in table 1 . Results of the analysis indicated that the soils are alkaline and medium to fine in texture. The organic matter content in the samples ranged between 0.569 and $1.517 \%$, $\mathrm{pH}(8.34-8.49)$, EC $(0.13-0.16 \mathrm{ds} / \mathrm{m})$, sand $(50-$ $60 \%)$, silt (28 - 38.5\%), clay (11.5 - 12\%), and textural class from sandy loam to loam. 
Table 1: Physicochemical properties of the soil from different stations

\begin{tabular}{ccccccccccc}
\hline $\begin{array}{c}\text { Station } \\
\text { no. }\end{array}$ & $\begin{array}{c}\text { Sand } \\
(\%)\end{array}$ & $\begin{array}{c}\text { Silt } \\
(\%)\end{array}$ & $\begin{array}{c}\text { Clay } \\
(\%)\end{array}$ & $\begin{array}{c}\text { Soil } \\
\text { textural } \\
\text { class }\end{array}$ & $\begin{array}{c}\text { Organic } \\
\text { matter } \\
(\%)\end{array}$ & $\begin{array}{c}\mathrm{pH} \\
(1: 2.5)\end{array}$ & $\begin{array}{c}\mathrm{EC} \\
(\mathrm{ds} / \mathrm{m})\end{array}$ & $\begin{array}{c}\mathrm{Mn} \\
(\mathrm{ppm})\end{array}$ & $\begin{array}{c}\mathrm{Zn} \\
(\mathrm{ppm})\end{array}$ & $\begin{array}{c}\mathrm{Fe} \\
(\mathrm{ppm})\end{array}$ \\
\hline $\mathrm{S} 1$ & 50 & 38.5 & 11.5 & Loam & 0.845 & 8.39 & 0.16 & 0.77 & 4.80 & 5.20 \\
$\mathrm{~S} 2$ & 60 & 28 & 12 & $\begin{array}{c}\text { Sandy } \\
\text { loam }\end{array}$ & 1.517 & 8.34 & 0.14 & 0.07 & 20.90 & 5.40 \\
$\mathrm{~S} 3$ & 50 & 38 & 12 & Loam & 0.569 & 8.49 & 0.13 & 2.80 & 2.94 & 6.60 \\
\hline
\end{tabular}

The residues of Dimethoate and Omethoate were detected at concentrations ranging from 0.914 to $5.180 \mathrm{mg} / \mathrm{kg}$ and 0.001 to $0.067 \mathrm{mg} / \mathrm{kg}$ air-dried soil respectively, table 2 .

Table 2. Arthropods population in control and Dimethoate treated farms and Dimethoate and Omethoate residues in the $0-15 \mathrm{~cm}$ soil layer of Zendan Valley after 5 days of application.

\begin{tabular}{|c|c|c|c|c|c|}
\hline \multirow[t]{2}{*}{ Station No. } & \multirow{2}{*}{$\begin{array}{l}\text { Sub- } \\
\text { Station } \\
\text { No. }\end{array}$} & \multirow{2}{*}{$\begin{array}{c}\text { Dimethoate } \\
\text { Residues in Treated } \\
\text { Station } \\
\text { (mg/kg air dried soil) }\end{array}$} & \multirow{2}{*}{$\begin{array}{c}\text { Omethoate } \\
\text { Residues in Treated } \\
\text { Station } \\
\text { (mg/kg air dried soil) }\end{array}$} & \multicolumn{2}{|c|}{$\begin{array}{l}\text { No of arthropods extracted } \\
(\text { Mean } \pm \text { SEM })\end{array}$} \\
\hline & & & & Control farms & Treated farms \\
\hline \multirow{3}{*}{ Upstream } & 1 & 0.914 & 0.005 & $6.60 \pm 1.53$ & $3.30 \pm 0.58$ \\
\hline & 2 & 1.568 & 0.006 & $12.00 \pm 2.00$ & $2.60 \pm 0.58$ \\
\hline & 3 & 5.180 & 0.020 & $7.67 \pm 1.53$ & $2.00 \pm 1.00$ \\
\hline \multirow[t]{4}{*}{ Midstream } & 4 & 5.068 & 0.020 & $6.00 \pm 1.00$ & $3.33 \pm 0.58$ \\
\hline & 5 & 2.324 & 0.014 & $15.00 \pm 2.00$ & $4.33 \pm 1.53$ \\
\hline & 6 & 1.368 & 0.001 & $14.00 \pm 2.52$ & $7.00 \pm 1.00$ \\
\hline & 7 & 3.157 & 0.067 & $9.00 \pm 1.00$ & $0.00 \pm 0.00$ \\
\hline \multirow[t]{2}{*}{ Downstream } & 8 & 2.028 & 0.032 & $4.33 \pm 0.58$ & $2.33 \pm 0.58$ \\
\hline & 9 & 1.413 & 0.021 & $15.67 \pm 1.53$ & $6.00 \pm 2.00$ \\
\hline
\end{tabular}

Various groups of soil microarthropods inclusive of mites, collembolans, beetle larvae, trips, cutworms, symphyla and seed corn maggot were extracted. Among these, mites form the major fauna followed by collembolans, table 3 .

Table 3. Soil micro-arthropods extracted from different stations:

\begin{tabular}{ccc}
\hline \multicolumn{2}{c}{ Table 3. Soil micro-arthropods extracted from different stations: } \\
\hline Station No. & Microarthropods extracted from control farms & $\begin{array}{c}\text { Microarthropods extracted from treated } \\
\text { farms }\end{array}$ \\
S1 & Mite spp., Collembolan spp. and Trips spp. \\
S2 & Mite spp. Collembolan spp.Seed corn maggot & Mite spp. and Collembolan spp. \\
S3 & Mite spp., Collembolans spp., Syphyla spp., Cut \\
& worm and Beetle larvae
\end{tabular}

The numbers of soil fauna in different treatments as against the untreated control are given in table 2.

These values indicated that the collected soil samples were good representatives of the agricultural soils in Zendan Valley and estimating residual Dimethoate in these samples gave a correct picture about the status of Dimethoate residues in the agricultural soils in the valley.
Once the level of soil contamination with Dimethoate is greater than $0.5 \mathrm{mg} / \mathrm{kg}$ it is considered higher than the "Total Threshold Limit Concentration" (TTLC) for total Dimethoate in soil. The data indicate that all the levels of residual Dimethoate in the analyzed soil samples collected from $0-15 \mathrm{~cm}$ soil layer after 5 days of Dimethoate application from different

Mohammed Ahssan Al-Haifi; M. Z. Khan; Abdullah Murshed; Ghole, V S 
substations were beyond the TTLC of Dimethoate in soil $(0.5 \mathrm{mg} / \mathrm{kg})$. This contamination may disturb the equilibrium of the ecosystem. Dimethoate Task Force (DTF) (1991) reported the Dimethoate residues in the UK studies Riverside was $0.13 \mathrm{mg} / \mathrm{kg}$ air dried soil after 5 days of application (1.2 kg/ha) in a clay loam soil. Cheminova (1993) in the New York studies reported that the Dimethoate residues was 0.59 $\mathrm{mg} / \mathrm{kg}$ in $0-15 \mathrm{~cm}$ sandy loam soil layer treated with Dimethoate formulated as $25 \%$ wettable powder at rate of $4.5 \mathrm{~kg} / \mathrm{ha}$. In the Texas studies the Dimethoate residues was $0.32 \mathrm{mg} / \mathrm{kg}$ in a $0-15 \mathrm{~cm}$ silt loam soil layer after six days of application in the rate of $1.7 \mathrm{~kg}$ ai/ha formulated as Dimethoate $43.5 \%$ ai EC. Due to the dry condition of the area, degradation of Dimethoate in the soil is slow and this lead to the persistence of Dimethoate residues in the agriculture soil for long time. On the other hand Puurtinen and Martikainen (1997) reported that Dimethoate appeared to be less toxic in dry soil than in moist soil. Toxicity of Dimethoate on collembolans tended to last longer at low temperature (Martikainen and Rantalainen, 1999). The effect of Dimethoate on the soil micro-arthropods might not be directly on soil micro-arthropods; it may be mediated by the primary effect on the food of the micro-arthropods or by the effect on the symbiotic micro-flora of the microarthropods rather than on the micro-arthropods itself. It can be seen that Dimethoate significantly reduced the population of the soil micro-arthropods (table 2); mites and collembolans were the most affected micro-arthropods by Dimethoate, table 3

The values of residual Dimethoate detected in the study area are giving a picture of the use of such agrochemicals beyond the carrying capacity of the soil environment in such areas at the time its use is banned in the developed countries. From these results, one can relate the decline of soil micro-arthropods population in farms where Dimethoate is being used due to the Dimethoate and Omethoate residual effect. The analysis of Dimethoate and Omethoate residues in soil sample collected from treated substation number three, shows the highest residual concentration in the soil samples collected from the upstream of the valley $(5.180 \& 0.020 \mathrm{mg} / \mathrm{kg}$ dry weight soil respectively), which correlates with the significant reduction of soil micro-arthropods in the upstream, table 2. From table 2 also, the highest concentration of Dimethoate and Omethoate residues $(5.068$ \& $0.020 \mathrm{mg} / \mathrm{kg}$ dry weight soil respectively), were detected in the soil sample collected from sub-station number one in the midstream of the valley, which correlates with the lowest number of microarthropods presented in this station as compare to the control substations, table 2 . The same effect has been seen in the low stream in which highest concentration of Dimethoate and Omethoate residues (3.157 \& $0.067 \mathrm{mg} / \mathrm{kg}$ dry weight soil respectively) were detected in the soil sample collected from treated sub-station number one, which correlates with the maximum declination of the soil micro-arthropods, table 2. The decline of the soil fauna population gave good information about the direct or indirect effects of Dimethoate and its metabolite (Omethoate) on the soil ecosystem in this valley.

The present outcomes agree with the results of Rajagopal et al. (1990). They reported that the insecticides such as Chloropyrifos, Carbosulfan, Phorate and Isofenphos showed significant effect on the non-target soil fauna, which included mainly mites and collembolans. Salminen et al. (1995) reported the effect of Pentachlorophenol (PCP) on soil fauna. A large numbers of collembolan Willemia anophtalma were lowered at the highest PCP concentration. The effect of Dimethoate is species specific, Folker-Hansen et al. (1996) reported the effect of Dimethoate on the body growth of representatives of the soil mesofauna and it was proved to be sex and species specific. All the collembolans species displayed a sexual dimorphism for body length, and females grew longer than the males in the case of treatment with Dimethaote. Diversity, a measure of community structure, was higher in control farms, while Dimethoate application reduced the soil fauna diversity, table 3 . In station one Trips spp disappeared in the treated farms whereas they were present in the control farms. In station two collembolans spp and seed corn maggots disappeared in the treated farms whereas they were present in the control farms. On the other hand Collembolans spp, Symphyla spp and beetle larvae were absent in the treated farms whereas at the same time they were present in the control farms in station number three. Everts et al (1989) reported that fields, which were mechanically treated against weeds, had higher species diversity than fields chemically treated by Deltamethrin, Fenitrothion \& Bromophose-ethyl. The present results are supported by the report of Kip Stavenson et al (2002); he reported that pesticide free cornfields had soil invertebrates' densities that were significantly higher than in the treated cornfields.

Entering the pesticides into the ecosystem may imbalance the ecological equilibrium. Rogers and Potter (2003) studied the effect of spring imidacloprid application for white grub control on parasitism of Japanese beetle (Coleoptera: Scarabaeidae) by Tiphia vernalis (Hymenoptera: Tiphiidae). They indicated that applying imidacloprid in early spring can interfere with biological control by $T$. vernalis, whereas postponing preventive grub treatments until June or July, after the wasps' flight period, will help to conserve $T$. vernalis population. These deleterious effects greatly modify some biological functions, such as soil organic matters decomposition and nutrient availability in the soil by reduction of the diversity of soil biota, (Ferraro and Pimentel, 2000). From the outcomes of this study, we can conclude that Dimethoate residues in the soil of Zendan Valley are beyond the TTLC for total Dimethoate in soil. Soil micro-arthropods density and diversity are low in the contaminated soil with Dimethoate and Omethoate, this will lead to the reduction of agriculture production for such areas and so lower the economy of the country. Therefore, we recommend

Mohammed Ahssan Al-Haifi; M. Z. Khan; Abdullah Murshed; Ghole, V S 
application of such chemicals should be under the insight and the control of some expert organizations such as Agriculture Ministry. The farmers should be trained, and the concern institutions should give environmental awareness courses to them.

\section{REFERENCES}

Al-Munibari Mahasen Excutive Summary, The Socioeconomic, Agricultural and Environmental Implication of Qat Production/Consumption in Yemen, Sana'a Office, on world wide web at http://www.fes-yemen.com

Dimethoate, on world wide web at http://www.fao.org/DOCREP/003/X2570E/X2570E07 . htm

Dimethoate/Omethoate/Fermothion, Dimethoate Task Fors and Cheminova Report, pp381-399. on world wide web at http://www.fao.org/WAICENTIFAOINFO/AGRICUL T/AGP/AGPP/Pesticide/JMPR/Download/98_eva/dim ethoate.pdf

Epstein D. L., Zack R. S., Brunner J. F., Gut L. and Brown J. J. (2000) Effects of broad-spectrum insecticides on epigeal arthropods biodiversity in Pacific Northwest apple orchards. J. Environ. Entomol. 29:2 340-348.

Everts JW, Aukema B, Hengeveld R and Koeman JH (1989) Side effects of pesticides on ground-dwelling predatory arthropods in arable ecosystems. Environ. Pollut. 59:3 203-25.

Ferraro Diego O. and Pimentel David (2000) Pesticides in agroecosystems and their ecological effect on the structure and function of soil faunal population. Journal of the Rachel Carson Council 2:2 47.

Folker-Hansen Pernille, Paul Henning Krogh and Martin Holmstrup, 1996. Effect of dimethoate on body growth of representatives of the soil living mesofauna, Ecotoxicology and Environmental Safety 33: 207-216.

Gupta (2000) Soil, plant, water and fertilizer analysis, Agrobios (INDIA)
Guide of Pesticide Use in the Republic of Yemen, Agriculture and Water resources Ministry (1990).

Kip Stevenson, Richard V. Anderson and Gerald Vigue (2002) The Density and Diversity of Soil Invertebrates in Conventional and Pesticide Free Corn, Transaction of the Illinois State Academy of Science 95:1 1-9.

Rajgaopal D., Prasad Kumar and Gavi Gowda (1990) Effect of newer granular insecticides on soil fauna in groundnut cropping system. J. Soil Biol. Ecol. 10:1 36-40.

Redak Richard A., Arthropods and Multispecies (2000) Habitat Conservation Plans: Are WE Missing Something? Environmental Management 26:1 S97S107.

Rogers ME and Potter DA (2003) Effect of spring imidacloprid application for white grub control on parasitism of Japanese beetle (Coleoptera: Scarabaeidae) by Tiphia vernalis (Hymenoptera: Tiphiidae), J. Econ. Entomol. 96:5 1412-9.

Martikainen E. and Rantalainen ML (1999) Temperaturetime relationship in collembolan response to chemical exposure, Ecotoxicol. Environ. Saf. 42:3 236-44.

Puurtinen HM and Martikainen EA (1997) Effect of soil moisture on pesticide toxicity to an enchytraeid worm, Enchytraeus sp. Arch Environ Contam. Toxicol. 33:1 34-41.

Salminen J, Haimi J, Sironen A and Ahtiainen j (1995) Effect of pentachlorophenol and biotic interactions on soil fauna and decomposition in humus soil. Ecotoxicol. Environ. Saf. 31:3 250-7.

TNO Laboratories Netherland on world wide web at http://uk.unifloor.nl/default.asp?080000000000/001

Veeresh G. K. and Rajagopal D. (1989) Applied Soil Biology and Ecology, pp. 317-343, in Pesticides and soil fauna; G. K. Veeresh; Oxford and IBH Publishing Co. Pvt. Ltd. 